\title{
Protocols for Dental Am Data Management in Disaster Victim Identification
}

\author{
*Eddy De Valck \\ Chief Forensic Odontologist DVI Belgium, Belgium
}

Submission: August 16, 2017; Published: August 29, 2017

*Corresponding author: Eddy De Valck, Chief Forensic Odontologist DVI Belgium, Parklaan 10 -1852 BeigemBelgium, Email: eddy.de.valck@telenet.be

\begin{abstract}
Disaster Victim Identification (DVI) is mainly based on the comparison of Ante Mortem data of the missing persons and Post Mortem data of the victims. Odontology, being one of the primary identification methods, plays a very important role in victim identification on the condition that dental ante mortem data are available and accessible. The collection and handling of these dental ante mortem data has to be carried out according to existing protocols to ensure the quality and processing of the data. Proper management of these incoming ante mortem dental data is an absolute necessity as a tool for correct victim identification. The dental Ante Mortem data manager has a primary role in the final victim identification process as collecting, checking, transcribing and storing these data is one of the most crucial processes in the outcome of the identification process. It is at the same time one of the most challenging and difficult task in the overall victim identification process. The forensic odontologist responsible for this section should be experienced, well trained and familiar with the whole process of dental Ante Mortem data collection and management and victim identification.
\end{abstract}

Keywords: DVI; Forensic Odontology; Dental AM data; AM data management; Dental records; Protocols

\section{Introduction}

The identification of victims of major disasters will be done after assessment of multiple factors. The degree of body condition will mainly determine which factors or methods can be taken into consideration for application as a base for identification. Identification in cases of disasters must always be based on scientifically sound, reliable methods, applicable under field conditions and capable of being implemented within a reasonable period of time. (Ref Interpol DVI guide) The primary and most reliable methods of identification are comparative dental analysis fingerprint analysis, and DNA analysis (Figure 1).
Fingerprint analysis

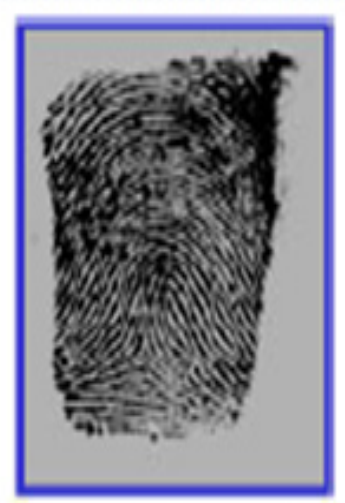

Forensic dental analysis

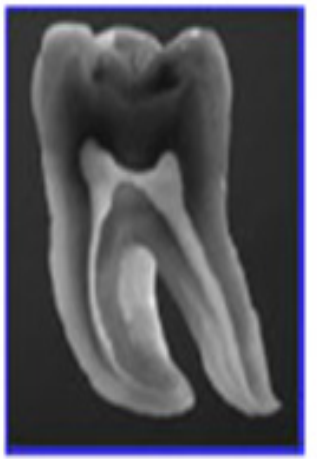

DNA analysis

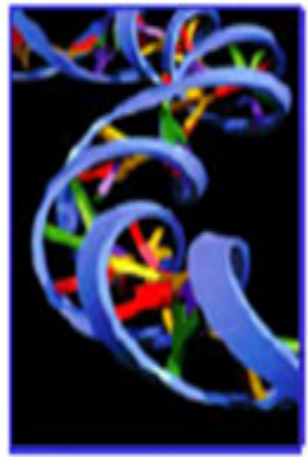

Figure 1: Primary identification methods. 
Secondary methods of identification include personal description, medical findings as well as evidence and clothing found on the body. These means of identification serve to support identification by other (secondary) means but do not provide sufficient scientific evidence and are thus not sufficient as a sole base of identification. All possible methods - primary and secondary-should be used as part of the whole identification process to lead to the identification of the presumed victims. The odontological identification of unknown subjects is mainly based on the comparison of dental AM (ante mortem) and PM (post mortem) elements. This was a common technique already used in a number of historical cases. The origin of the AM information in some of these cases came from several sources of documentary evidence. Oral testimony from family, treating dentist(s) and/or dental technician(s), written evidence and/ or drawings from dental records, X rays, dental casts, close up photos were used to establish a dental AM record from the alleged victim [1,2](Figures $2 \& 3$ ).
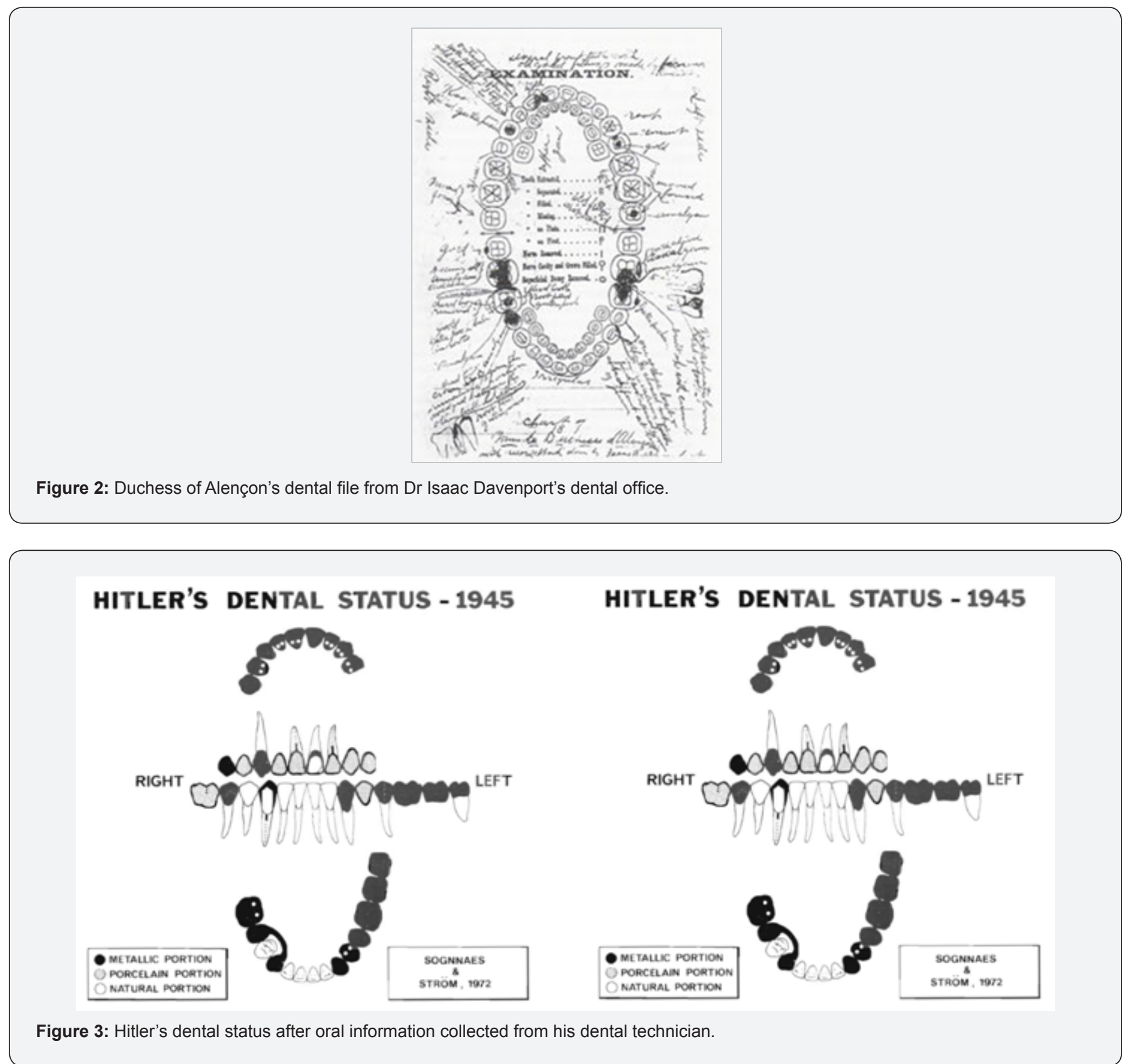

As dental practice and practice management have changed tremendously in the past decades the kind and source of dental AM information obtained from treating dentists in present times has different origins and could/ should be considered to be more correct and complete and thus more valid than in those earlier days. Dental administration software programs do or should produce a more accurate AM record than the handwritten notes from the past but are still sensible to human errors. The fact that 
a lot of countries do not have a stringent legislation on dental record keeping though may leave the forensic odontologist in identification cases with an enormous problem. Even in countries with a strict legislation on the content and the time a dental record has to be kept we still face the fact that not all patient dental records do match these legal requirements [3]. This may of course create problems when attempting to create a consistent, correct, and valid AM dental record. Moreover it will compromise the outcome of our efforts to establish the identity of the unknown victim(s).

In addition to the AM - PM comparison to establish identity, odontologists are also able to provide additional information about certain aspects of a person's life or lifestyle by examining the teeth. These can be valuable when searching ante mortem data-bases for potential matches. Age estimation by evaluating the dental developmental stages is very useful in establishing the chronological age at the time of death [4,5]. It might be possible based on the type of dental treatment or materials used to estimate the country or region of origin for a given victim.
These can then be used to limit or restrict the population to search for possible ante mortem data.

\section{Ante Mortem Data Management}

The most important requirement for victim identification work is the application of international standards and protocols, which are the common basis for the work in multinational DVI operations. All measures are designed to contribute to the positive identification of victims. The Interpol DVI Guide provides guidelines for use by Interpol Member States in the identification of disaster victims [6]. It is of outmost importance in the immediate aftermath of a major disaster that an accurate list of missing persons is established in order to collect the $\mathrm{AM}$ information from the potential disaster victims as quick as possible. This may take considerable more time and effort in an open disaster than in a closed disaster as neither the number nor identity of the victims is known. The AM Team, integrated within the chain of command, is initially tasked with collecting and recording all information relating to individuals who may be regarded as potential disaster victims (Figure 4).

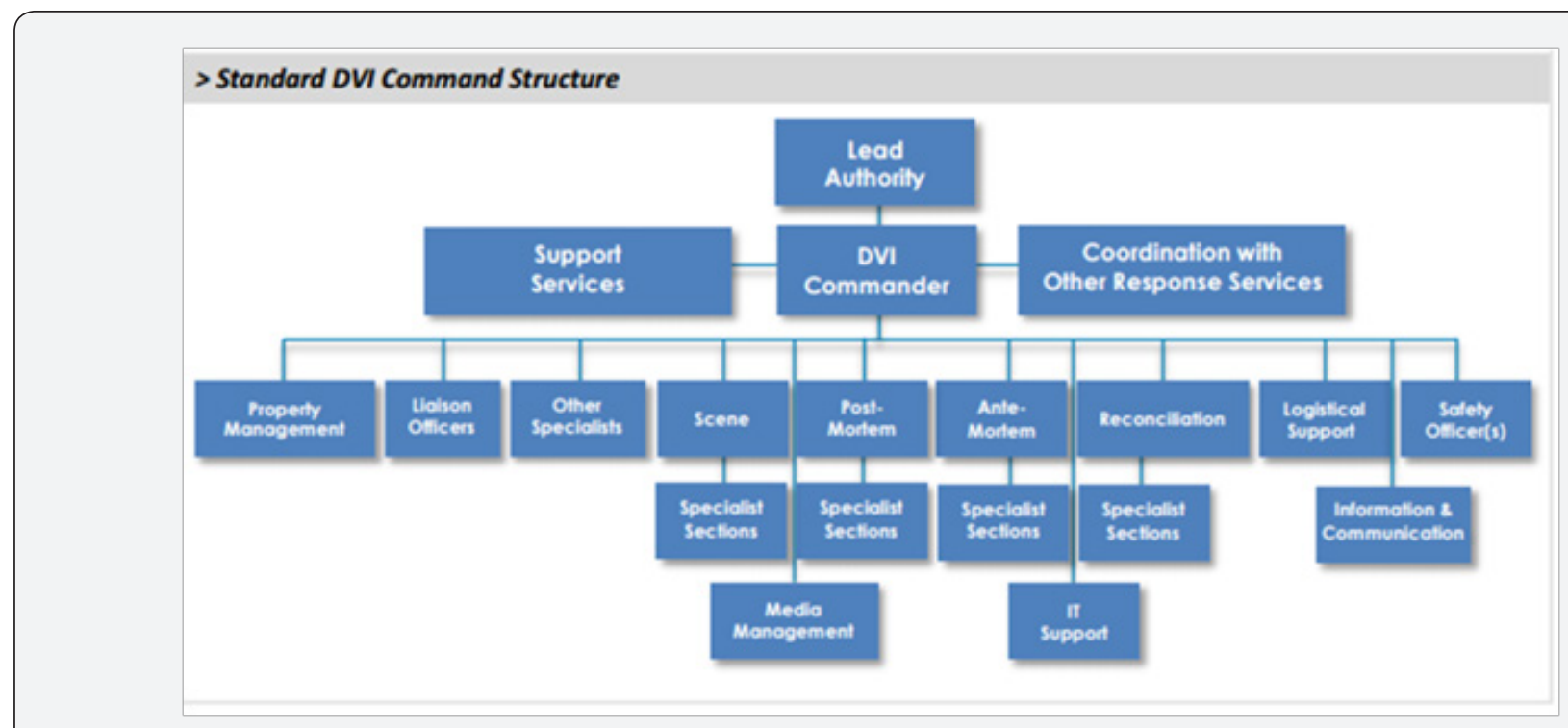

Figure 4: Standard DVI Command Structure as shown in DVI Interpol Guide.

The AM Team collects ante mortem data required for the identification of victims, but should not begin collecting AM data from relatives, friends, etc. until a reliable list of actual victims is available. They also prepare corresponding missing-persons files and notify the relevant authorities regarding completed identifications.

AM Teams should ensure that all victim identification data is collected solely on the basis of the Interpol DVI Ante Mortem Form (yellow). It is also imperative to ensure that AM data are collected by the respective assigned specialists. The highest possible quality standards must be applied and protocols should be followed as written out. All AM data obtained are to be documented. This is important as it will allow team members to determine at a later stage what data was obtained from which relatives, friends, dentists, doctors, hospitals etc. by which team. A corresponding personal file should therefore be set up for every missing person for use in documenting all incoming and outgoing information relating to the individual in question. Collecting dental AM data is an absolute necessity in order to reconstruct and establish the AM dental status of the victim [7]. The odontologists working on the AM team will have to deal with questions like: Where? What? Who? And How? Where? The personnel charged of dental AM collection will obtain the name(s) of the victims' treating dentist(s) through family members. This part of the AM collection may be carried out by the police or social services members on the AM tea 
$\mathbf{A}_{\text {nte }} \mathbf{M}_{\text {ortem (vellow) }}$

INTERPOL DVI Form - Missing Person Odonolobgy 600's

Family name:

AM No:

First name(s):

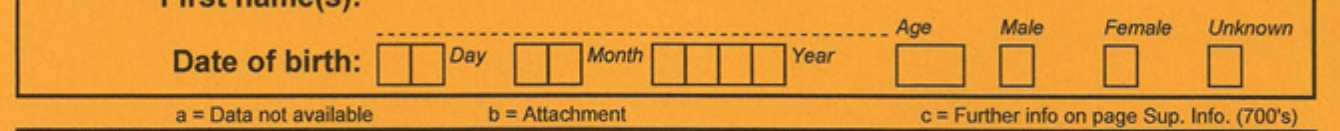

\section{ODONTOLOGY}

$=$ Data not available

b $=$ Attachment

\begin{tabular}{c|c|c|c|}
$c=$ Further info on page Sup. Info. (700's) \\
\hline a & b & C \\
\hline
\end{tabular}

600 Dentist/clinic

Name

Street / No.

Postcode / Town

State / Country

Phone / Email

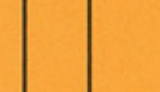

$01 \mathrm{P}$

\begin{tabular}{l|l}
\hline 605 & Dentist/clinic
\end{tabular}

605 Name

Street / No.

Postcode / Town

State / Country

Phone / Email

Tring

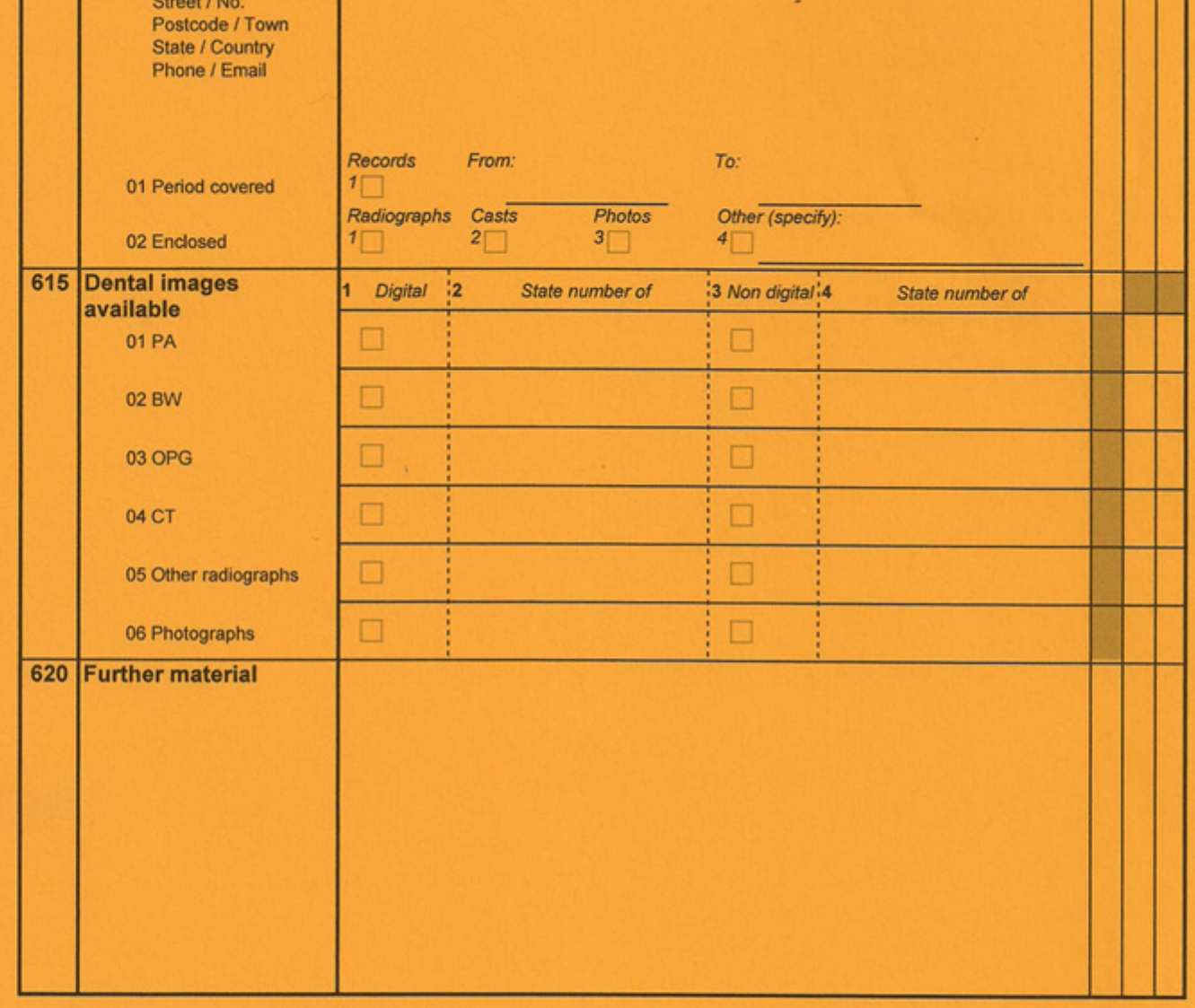

\begin{tabular}{|lll|l|}
\hline Collected by & Duty Title $\quad:$ & Signature / Date \\
& Name & $:$ & \\
& Address $\quad:$ & \\
& Phone / Email & $:$ & \\
\hline
\end{tabular}


$\mathbf{A}_{\text {nto }} \mathbf{M}_{\text {ortem (vellow) }}$

INTERPOL DVI Form - Missing Person 600 's Family name:

AM No:

First name(s):

$\underset{\mathrm{a}=\text { Data not avaliable }}{\text { Date of birth: } \square \square^{\text {Day }} \square \square^{\text {Month }} \square=\text { Attachment }}$ \begin{tabular}{|l|l|}
\hline ODONTOLOGY \\
\hline 630 & Dental findings (for primary teeth change specific FDI code) \\
\hline 11 &
\end{tabular}

\begin{tabular}{|l|l|l|l|}
\hline 630 & Dental findings (for primary teeth change specific FDI code) & 21 \\
\hline 11 & & & 22
\end{tabular}

\begin{tabular}{|l|l|l|l|}
\hline 11 & & & 21 \\
\hline 12 & & & 22 \\
\hline 13 & & & 23 \\
\hline 14 & & & 24 \\
\hline 15 & & & 25 \\
\hline 16 & & & 26 \\
\hline 17 & & & 27 \\
\hline 18 & & & 28 \\
\hline
\end{tabular}

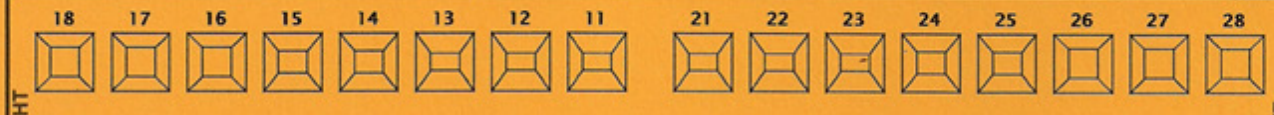
$\frac{5}{\mathscr{2}}$

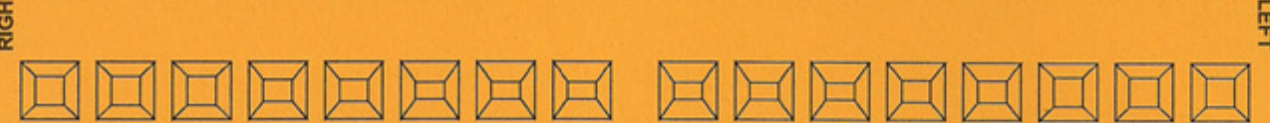

\begin{tabular}{|c|c|c|c|c|c|c|}
\hline 48 & & & & & & 38 \\
\hline 47 & & & & & & 37 \\
\hline 46 & & & & & & 36 \\
\hline 45 & & & & & & 35 \\
\hline 44 & & & & & & 34 \\
\hline 43 & & & & & & 33 \\
\hline 42 & & & & & & 32 \\
\hline 41 & & & & & & 31 \\
\hline \multirow[t]{3}{*}{635} & Specific data & & & & \begin{tabular}{|l|l} 
\\
\end{tabular} & \begin{tabular}{l|l}
$b$ & $c$ \\
$c$
\end{tabular} \\
\hline & 01 Specify & $1 \square$ Crowns & $2 \square$ Pontics & $3 \square$ Implants & & \\
\hline & & $4 \square$ Dentures & $5 \square$ Other & & & \\
\hline \multirow[t]{3}{*}{640} & Other findings & & & & & \\
\hline & 01 Specify & $1 \square$ Occlusion & $2 \square$ Tooth wear & $3 \square$ Periodontal status & & \\
\hline & & $4 \square$ Supemumeraries & $5 \square$ Stains & $6 \square$ Other & & \\
\hline \multirow[t]{2}{*}{645} & Type of dentition & & & & & \\
\hline & 01 Specify & $1 \square$ Primary dentition & $2 \square$ Mixed dentition & $3 \square$ Permanent dentition & & \\
\hline \multirow[t]{4}{*}{650} & Quality check & Date: & & Signature: & & \\
\hline & FOd 1 & FOd 1 Name: & & & & \\
\hline & & Date: & & [S̈ignature: & & \\
\hline & FOd 2 (ff available) & FOd 2 Name: & & & & \\
\hline
\end{tabular}

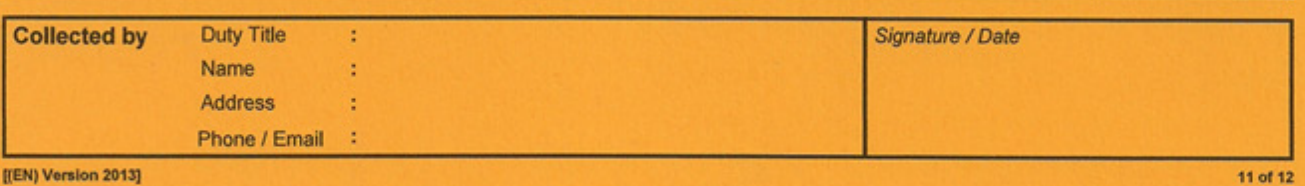

Figure 5: AM 600 pages for dental data registration. 
If no treating dentist is known to the family members this kind of information may be obtained through health insurance companies, insurance companies and other organizations dealing with dental care. What? It is mandatory that the AM team obtains the original records as they are necessary for the transcription of the data onto the yellow 600 pages (Figure 5). The patient's record should not only comprehend the treatments carried out by the dentist, but also the dental status of the patient at the first visit to the dental office. As prevention increases the number of teeth requiring dental restorations will decrease leaving less distinctive elements for identification. For that reason dental practitioners will have to register more often the natural anomalies and anatomical features that may be helpful in identification such as teeth rotations, diastema, tooth migrations or displacements, fractured or chipped teeth, fluorosis, hypoplasia, tooth jewelry, intrinsic staining, surnummerary teeth, microdonts, mandibulartori etc. A lot of this information may have to be included in the so called free text 700 pages of the Interpol forms [6] (Figure 6).
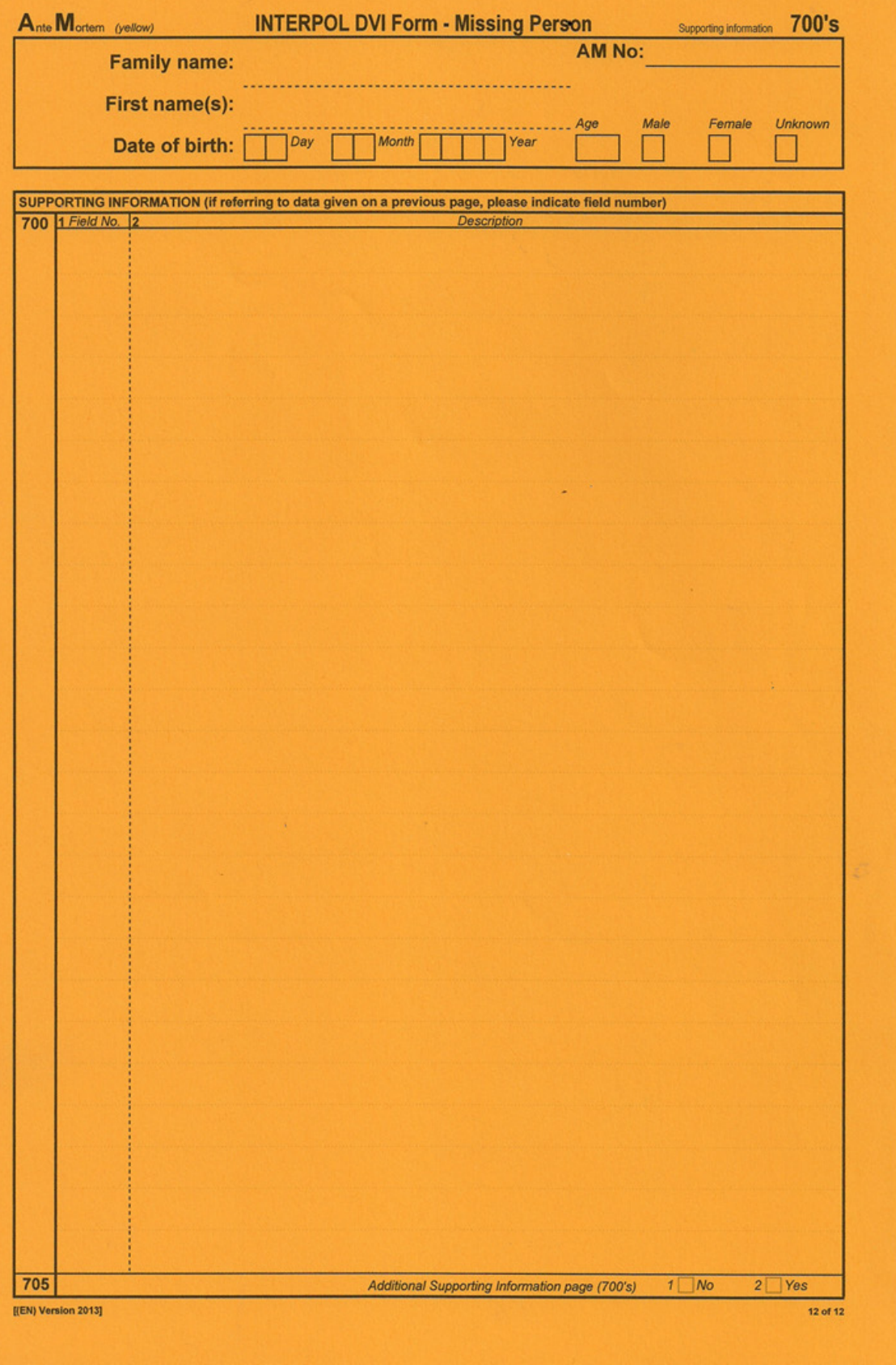

Figure 6: AM 700 page for free text data registration. 
Conventional and/or digital radiographs and/or scans of the teeth, jaws and/or skull are another indispensable part of the AM dental data that should be obtained. These radiographic images (bite wing, periapical, panoramic, occlusal $\mathrm{X}$ rays) provide a two dimensional view of teeth and the surrounding structures and will provide more individual AM features than a written record. CBCT scans provide three dimensional images and are even more valuable as a source of AM information and will reveal additional AM information on anatomical structures that are not noticed on radiographic images [8]. All original treatment records and radiographs images should be labelled with the name and date of birth of the patient, as well as dates of treatment, dates of exposure of radiographs, signature and contact information of the treating dentist (name, address, telephone number and email address).
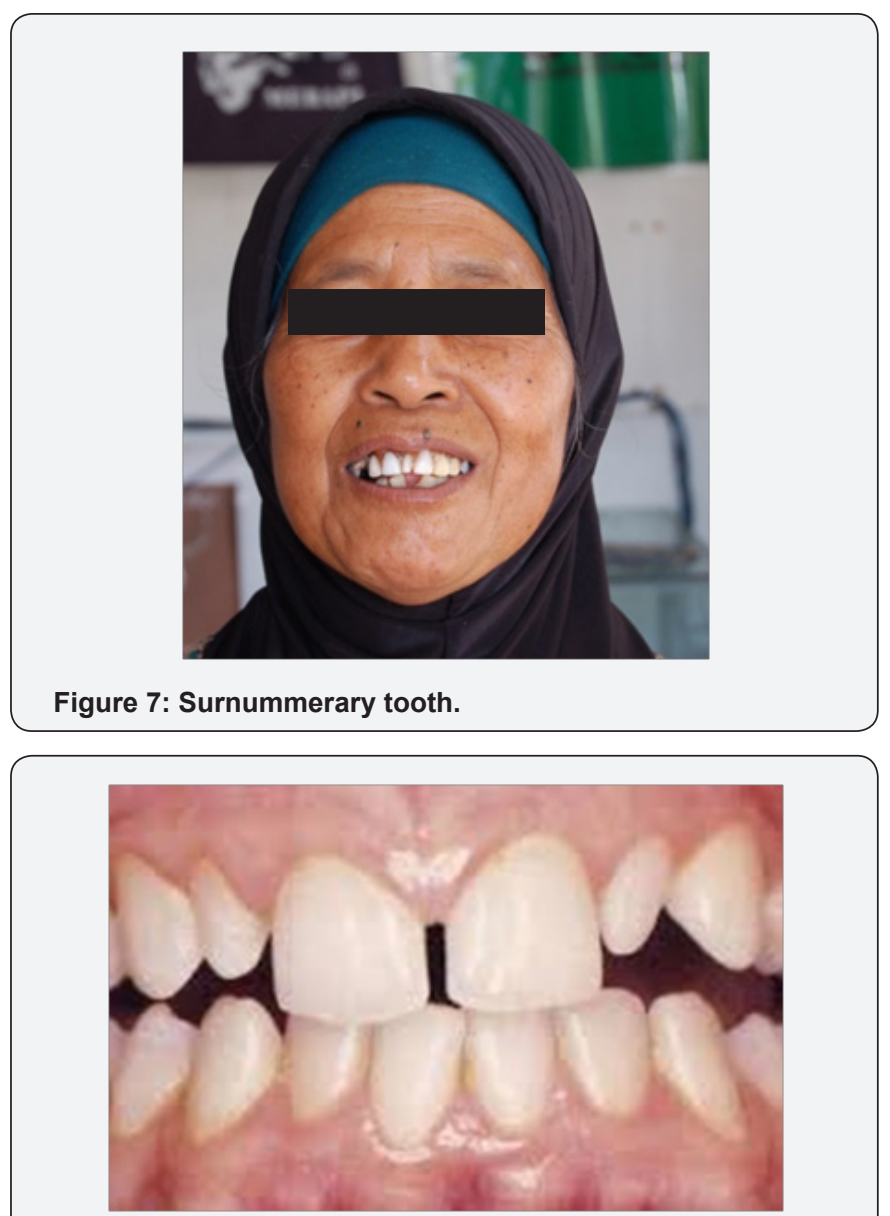

Figure 8: Microdont

Dental casts or models do provide three dimensiona information, they will be available after orthodontic or prosthodontic treatment and provide great detail for identification. Dental retainers will also show enough individuality to be used in comparison with PM data [9]. Close up photos with teeth showing unusual characteristics are also a great source of AM information especially when individual characteristics are shown (Figures 7-9). If the material and records cannot be obtained from the victim's dentist(s) there are other potential sources to be contacted for information gathering: dental specialists, dental technicians, school dental services, military organizations, correctional facilities, insurance companies.

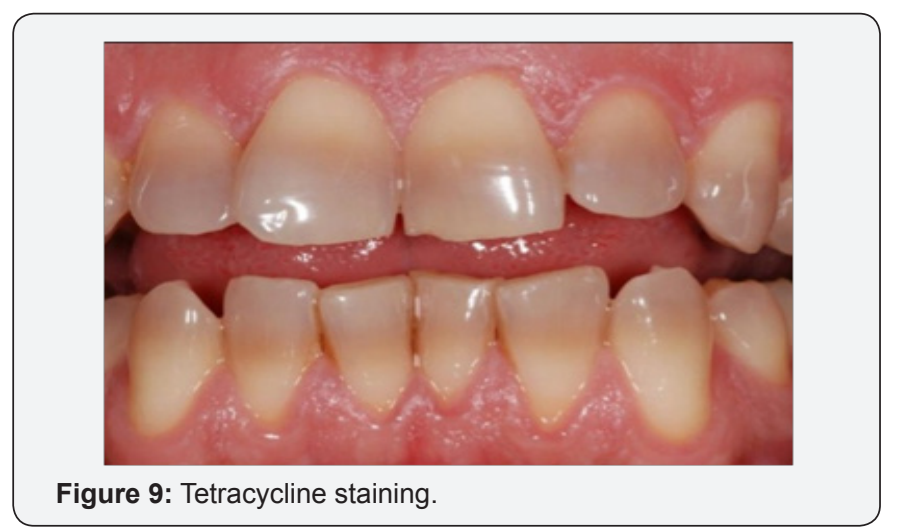

Who? It is recommend that the contact with the victim's dentist is made by the odontologist on the AM team as it may facilitate the communication between peers especially when the dentist does not want to release the victim's records, which is often the case. Hiding behind the medical secret is an excuse which is very often used to cover the fact that insufficient or no dental records are available. How? Searching for the victim's dentist(s) may be done by police and social services on the AM team. Contacting the dentist(s) is preferably done by the AM team forensic odontologist as it facilitates the communication on which information is needed. The collection of all AM dental data may be done by the police and the dental AM information should be handed over under a sealed envelope to the attention of the odontologist on the AM team. This will be done accordingly the Interpol DVI protocols and respecting the medical secret.

Although speed is essential in obtaining the dental AM information it should never be at the expense of quality of the data. In forensic odontology and in DVI in particular, accurate detailed, complete and correct recording of antemortem information is essential as the basis for odontological identification. Earlier studies in Sweden ${ }^{3}$ indicated that the quality of the recording procedure was not always acceptable. The aim of this retrospective study was to investigate the quality of ante-mortem records and its possible implications for identification work. Information on dental characteristics, normal anatomical findings and restorative treatment was complete in $43(68 \%)$ of the cases, incomplete in $17(27 \%)$ and missing in $3(5 \%)$. Registration of previous therapy was missing in about $75(94 \%)$ of the records. It was possible to identify patient radiographs in only 16 of the 40 records where radiographs were available. Despite of these figures this did not seem to compromise the effect of the identification which could be explained by the presence of other circumstantial elements for identification. 


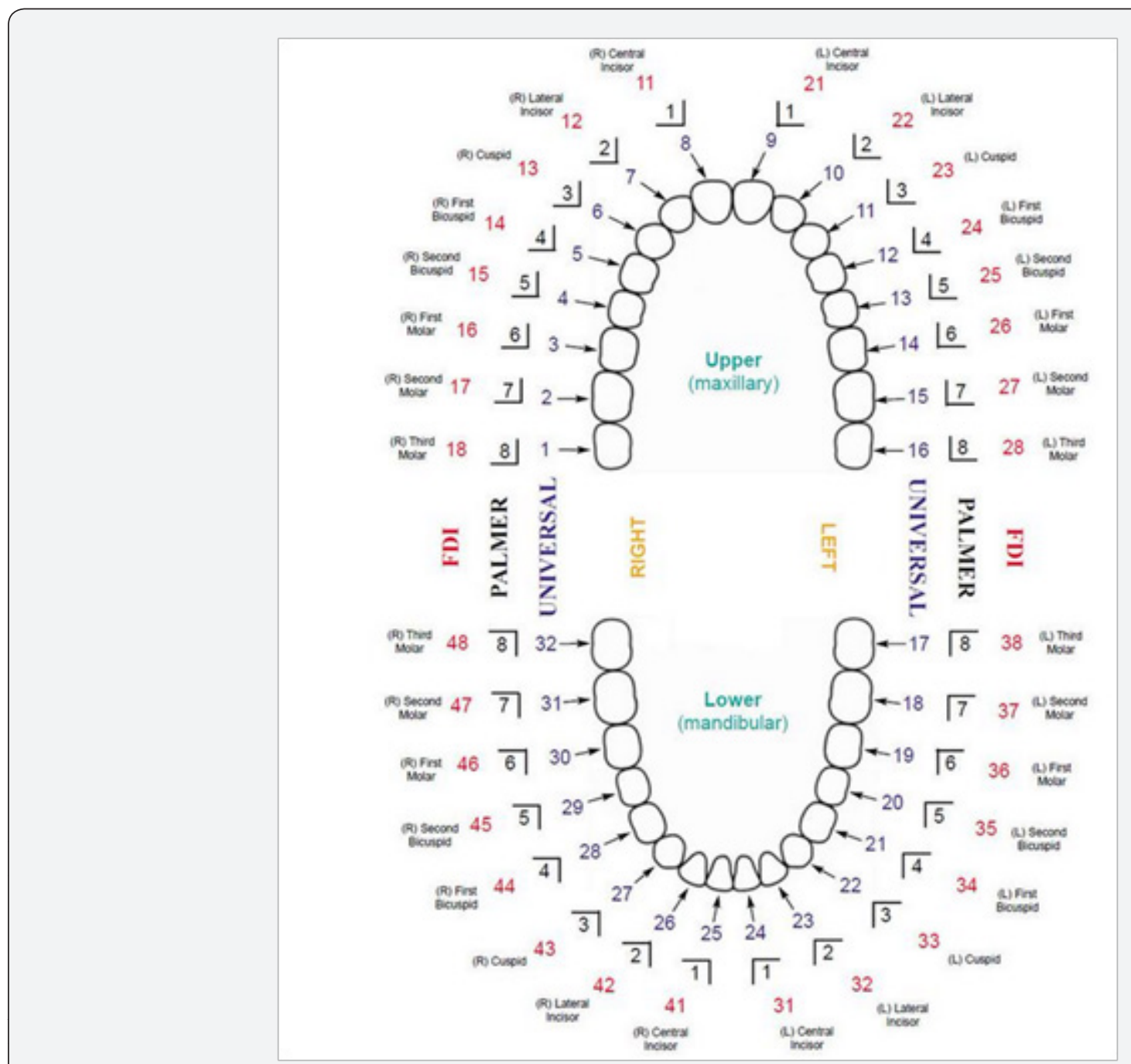

Figure 10: Some tooth numbering systems with the preferred Two Digit system ( FDI) in red.

\section{Dental Am Data in the Reconciliation Team}

The Reconciliation Team is responsible for matching AM and PM data records, which ultimately leads to victim identification. Considerable time can be saved if a data processing and comparing software is used especially when there are a lot of data to be processed. This computer program however is only a comparing tool and a final decision on identification should only be made after manual comparison. The director of the reconciliation team must be a senior specialist who must have a grasp of all aspects of the identification process and will be assisted by experienced specialists from the different sections.

The forensic odontologist on the reconciliation team will be responsible in the first place for the Quality Assurance of AM and PM data [11-13]. This involves management of the incoming AM dental data such as the origin, the content and the time of reception. If necessary the dentist(s) who delivered the AM information will be contacted to clarify elements in the AM records. Comparison of data in Plass Data if available will be carried out and lead to manual comparison of the AM/ PM data. Since this may be a very time consuming process it is recommended to use key markers for each subgroup. In this way noteworthy features from the missing person or the unknown body are listed.

Comparison of the AM and PM dental data will lead to a number of possible conclusions:

a) Positive identification: the $\mathrm{AM}$ and PM data match in enough details with no unexplainable discrepancies to conclude they are from the same individual.

b) Possible identification: the $\mathrm{AM}$ and $\mathrm{PM}$ data have consistent features, but because of the quality of either the AM or PM data, are not sufficient to conclude to a positive identification.

c) Insufficient evidence: the available AM and/or PM information is insufficient to lead to a positive conclusion about identification. 
d) Exclusion: there is no match possible between AM and PM data.

The forensic odontologist will be responsible for preparation of expert opinions for matches and in cases in which matches are identified, the Reconciliation Team submits the corresponding documents to the Identification Board for review and final decision. The forensic odontologist on the reconciliation team will support the Director at the ID Board.

\section{Dental Am Data in the Identification Board}

The Identification Board which meets at regular intervals to discuss and verify the proposals submitted by the Reconciliation Team is responsible for the final identification of every victim and should therefore be composed of the most experienced identification experts involved in the entire operation, i.e. the heads of the various sections/units (forensic pathology, odontology, fingerprints) and the Director of the DVI Team. The ID Board makes final decisions regarding the identification of given victims after reviewing and evaluating the evidence in favor of identification in a given case and certifies these decisions on the DVI form in a Victim Identification Report with approval by signature. This record is then regarded as formal confirmation of the identification of a deceased disaster victim.

\section{Conclusion}

Odontology as one of the primary identification methods in DVI has been proven to be a quick, cheap, scientific and reliable mean of identification. Experiences from previous disasters have shown that collection of dental AM data is the most challenging part in the victim identification process and that good management of the full AM data process has to be done according to existing protocols and processes in order to lead to a positive identification. The forensic odontologist (s) have a crucial position in the different sections of the AM team and it is of outmost importance they are familiar with the whole AM data management process which is written down in the Interpol DVI comprehensive guide.

\section{References}

1. Reidar F Sognnaes, Ferdinand Ström (1973) The odontological identification of Adolf Hitler: Definitive documentation by X-rays, interrogations and autopsy findings. Acta Odontologica Scandinavica 31(1): 1-27.

2. Riaud Xavier (2015) Dr Oscar Amoëdo y Valdes (1863-1945), Founding Father of Forensic Odontology. Global Journal of Anthropology Research 2: 22-25.

3. Borrman H, Dahlbom U, Loyola E, N Rene (1995) Quality evaluation of 10 years patient records in forensic odontology. Int J Leg Med 108(2): 100-104.

4. TY Marroquin, S Karkhanis, SI Kvaal, S Vasudavan, E Kruger, et al. (2017) Age estimation in adults by dental imaging assessment systematic review. Forensic Science International 275: 203-211.

5. Richard B Bassed, Anthony J Hill (2011) The use of computed tomography (CT) to estimate age in the 2009 Victorian Bushfire Victims: A case report, Forensic Science International 205(1-3): 48-51.

6. Interpol DVI Guide (2014).

7. Eddy De Valck (2006) Major incident response: Collecting antemortem data, Forensic Science International 159: S15-S19.

8. Tim Thompson, Sue Black (2007) Forensic Human Identification: an introduction. London. Taylor and Francis Group p. 179-185.

9. A Franco, G Willems, PHC Souza, OM Tanaka, W Coucke, et al. (2017) Three dimensional analysis of the uniqueness of the anterior dentition in orthodontically treated patients and twins. Forensic Science International 273: 80-87.

10. S Manica (2014) A new website to aid the interpretation of antemortem dental records: www.internationaldentalcharts.org. J Forensic Odontostomatol 32(2): 1-7.

11. Aires Paiva de AZEVEDO, Renata Kelly Trajano NOGUEIRA, FlávioPinheiro FALCÃO, Suzana Papile Maciel CARVALHO (2015) Effectiveness of dental records in human identification, RGO, Rev. Gaúch. Odontol 63: 4.

12. Vilma Pinchi, Gian-Aristide Norelli, Fabio Caputi, Gianfranco Fassina, Francesco Pradella, et al. (2012) Dental identification by comparison of antemortem and postmortem dental radiographs: Influence of operator qualifications and cognitive bias. Forensic Science International 222(1-3): 252-255.

13. RE Wood, SL Kogon (2010) Dental radiology considerations in DVI incidents: A review. Forensic Science International 201(1-3): 27-32.

\section{Your next submission with Juniper Publishers will reach you the below assets}

- Quality Editorial service

- Swift Peer Review

- Reprints availability

- E-prints Service

- Manuscript Podcast for convenient understanding

- Global attainment for your research

- Manuscript accessibility in different formats

( Pdf, E-pub, Full Text, Audio)

- Unceasing customer service

Track the below URL for one-step submission https://juniperpublishers.com/online-submission.php 